\title{
Análise da cementação sólida com têmpera direta aplicada em engrenagens cilíndricas de dentes retos (módulo 2) de aço SAE 8620
}

Bruno Lessmann Fertig ${ }^{1}$

Jean Senise Pimenta ${ }^{l *}$ (D)

\section{Resumo}

Foram analisadas três condições de cementação sólida em engrenagens cilíndricas de dentes retos (módulo 2) de aço SAE 8620, sendo testados requisitos de dureza e profundidade da camada para seleção do melhor conjunto de parâmetros. O estudo prévio baseado na segunda lei de Fick (regime não estacionário) para a difusão de carbono atômico no Fe- $\gamma$ $\left(900^{\circ} \mathrm{C}\right)$ forneceu os tempos de cada experimento. Após a cementação, as peças foram submetidas à têmpera direta em óleo e posterior revenimento. Amostras foram removidas e preparadas por técnicas de macrografia, microscopia óptica e ensaios de microdureza na escala Rockwell C (HRC). A cementação foi eficiente porque houve formação de martensita junto à superfície e ao longo do contorno dos dentes das engrenagens, porém contendo uma provável dispersão de austenita retida. Resultados satisfatórios foram obtidos na cementação a $900^{\circ} \mathrm{C}$ por $2 \mathrm{~h} 19 \mathrm{~min}$, pois a dureza medida na camada cementada apresentou valores acima de $50 \mathrm{HRC}$ até profundidades entre $0,45-0,50 \mathrm{~mm}$ e, portanto, dentro da faixa de $0,40-0,60 \mathrm{~mm}$ (requisito para engrenagens de módulo 2).

Palavras-chave: Cementação sólida; Têmpera direta; Engrenagem; Aço SAE 8620.

\section{Analysis of pack carburizing followed by diretct quenching applied to spur gears (module 2) of SAE 8620 steel}

\begin{abstract}
Three conditions were analyzed for pack carburizing in spur gears (module 2) of SAE 8620 steel, being tested requirements of hardness and hardened layer depth to select the best set of parameters. A previous study based on Fick's second law (non-stationary regime) for diffusion of atomic carbon in $\mathrm{Fe}-\gamma\left(900^{\circ} \mathrm{C}\right)$ provided the times for each experiment. Immediately after carburizing, pieces were submitted to direct quenching in oil and subsequent tempering. Samples were removed from these pieces and prepared for macrography, optical microscopy and microhardness tests on Rockwell C scale (HRC). Carburizing was efficient because martensite was formed near the surface and along the contour of the gear teeth but containing a probable dispersion of retained austenite. Satisfactory results were obtained for pack carburizing at $900^{\circ} \mathrm{C}$ for $2 \mathrm{~h} 19 \mathrm{~min}$ because hardness measures inside of the hardened layer showed values above $50 \mathrm{HRC}$ until depths between $0.45-0.50 \mathrm{~mm}$ and, therefore, within the range $0.40-0.60 \mathrm{~mm}$ (requirement for module 2 spur gears).
\end{abstract}

Keywords: Pack carburizing; Direct quenching; Spur gear; SAE 8620 steel.

\section{Introdução}

Engrenagens são elementos de máquinas usados para transmitir movimento rotativo e torque entre eixos, sendo no geral cilindros dentados projetados para não haver travamento ou perda de contato entre os dentes. Uma engrenagem se refere ao conjunto de, pelo menos, duas rodas dentadas (uma motora e a outra movida) servindo para uma transmissão mecânica [1].
A engrenagem cilíndrica de dentes retos é o tipo mais comum na Mecânica; sendo projetada para que seus eixos estejam paralelos entre si girando em sentidos opostos, e no contato entre os dentes do conjunto seja transmitido um movimento circular contínuo de alta rotação $[1,2]$.

Aços de baixo-carbono ou de baixa-liga podem ser usados na fabricação de engrenagens em geral; pinhões;

${ }^{I}$ Instituto Federal de Santa Catarina - IFSC, Campus JAR-RAU, Jaraguá do Sul, SC, Brasil.

*Autor correspondente: jean.pimenta@ifsc.edu.br

2176-1523 (C) 2021. Fertig et al. Publicado pela ABM. Este é um artigo publicado em acesso aberto (Open Access) sob a licença Creative Commons Attribution, que permite uso, distribuição e reprodução em qualquer meio, sem restrições desde que o trabalho original seja corretamente citado. 
eixos-comando; entre outras peças [3-5]. Isto se justifica para que o material da peça seja submetido a um conjunto de tratamentos térmicos para que, então, seja formada uma fina camada abaixo da superfície que resulte em maior dureza, resistência à fadiga e ao desgaste no contato dos dentes, mantendo-se o núcleo da peça dúctil e tenaz. Por exemplo, o aço SAE 8620 é um aço baixa-liga em cromo, níquel e molibdênio que possui boa condição de temperabilidade e é indicado para o tratamento de cementação [6].

A cementação sólida é o mais antigo e econômico tratamento termoquímico para endurecimento superficial de peças, dentre outros existentes: a líquida; gasosa; cementação a plasma; e a cementação a vácuo (vácuo grosseiro e pressão parcial de gás hidrocarboneto); o controle do potencial de carbono é mais adequado no método gasoso ou no vácuo com baixa pressão $[5,7,8]$. Na cementação sólida, as peças são adequadamente colocadas dentro de caixas metálicas, sendo o conjunto aquecido na temperatura de austenitização do aço no geral entre $850^{\circ} \mathrm{C}$ e $1000^{\circ} \mathrm{C}[6,8]$. Esta faixa de temperaturas é importante para evitar problemas na temperabilidade do aço (aquecimento abaixo de $850^{\circ} \mathrm{C}$, p.ex.) e de crescimento anormal do grão na rede cristalina se associado a longos períodos de cementação. Nestas caixas coloca-se uma mistura carburizante rica no elemento químico endurecedor (o carbono). Durante a difusão do carbono para o interior do aço, o teor deste elemento aumenta junto à superfície se comparado ao núcleo da peça $[4,9]$.

As leis de Fick estabelecem importantes critérios para o estudo dos mecanismos de difusão atômica, sendo que grande parte destas situações na prática está no regime não estacionário. Neste caso, o fluxo difusional e o gradiente de concentração estão num ponto específico dentro do sólido variando com o tempo; adequadas condições de contorno possibilitam resolver a equação da segunda lei de Fick neste regime [9]. Dentre as suas variáveis, destaca-se aquela que indica a concentração constante na superfície do sólido, ou seja, a solubilidade máxima de carbono na fase austenita do aço; tal solubilidade é dependente da temperatura que o aço será submetido e de sua composição química [10].

O tratamento térmico de têmpera deve ser feito após a cementação, quando a peça será resfriada bruscamente num meio adequado para se obter martensita no aço $[4,6]$. A formação de uma fina camada endurecida abaixo da superfície da peça é viável graças à prévia difusão de carbono na fase $\mathrm{Fe}-\gamma$ do aço durante a cementação. A têmpera pode ser executada a partir de uma temperatura de austenitização logo após o fim da cementação (têmpera direta) ou, então, pela aplicação da têmpera na peça cementada depois do seu resfriamento ao ar e de um novo aquecimento. No caso da têmpera direta, tipicamente haverá alguma retenção de austenita na microestrutura martensítica - dependendo do percentual em volume desta fase, tal fato será benéfico ou não para a vida útil dos dentes da engrenagem $[5,6]$. Após a têmpera deve-se fazer o revenimento para alívio de tensões na rede cristalina, devido à formação da martensita. Este tratamento consiste em aquecer a peça numa temperatura abaixo da zona crítica por um tempo adequado, seguido de resfriamento dentro do forno [6,11]. O revenimento em aços cementados deve ser feito em temperatura reduzida no geral na faixa entre $150-180^{\circ} \mathrm{C}[4,5,12]$.

Rakhit [3] considera que grande parte das engrenagens fabricadas são endurecidas por têmpera direta em óleo após a cementação; entretanto, as engrenagens fabricadas de aços alta-liga são primeiramente resfriadas ao ar logo após a cementação a gás e, então, depois são reaquecidas e temperadas para se ter minimizado o grau de distorção nas peças. Aços usados na fabricação de engrenagens podem atingir uma dureza superficial em torno de 60 Rockwell C (HRC) nos dentes, enquanto a dureza junto ao núcleo pode variar entre 32-48 HRC [5]. No caso específico de aços baixa-liga, admite-se que a cementação possa aumentar o teor de carbono em até $0,40 \%$ (\% peso) para uma têmpera em óleo que também resulte uma apreciável ductilidade no núcleo da peça [2].

Garcia et al. [13] e Cardoso et al. [14] obtiveram resultados satisfatórios na execução de testes de cementação sólida em engrenagens cilíndricas de dentes retos (módulo 2) de aço SAE 4320; entretanto, a aplicação desta técnica apresenta dificuldades de um controle rigoroso da profundidade da camada cementada em componentes mecânicos [6]. Por este motivo é interessante avaliar neste tipo de cementação a reprodutibilidade dos resultados em função dos parâmetros selecionados nos testes, uma vez que estes mudarão em função do tamanho da peça.

A utilização do tratamento de cementação sólida é útil para casos de baixa necessidade de produção de peças, além da facilidade operacional e de não requerer grandes investimentos em infraestrutura. Tais aspectos são interessantes em específico para empresas de pequeno porte da área metalmecânica, justificando o uso desta técnica como uma solução tecnológica viável para endurecimento superficial de peças de aço. Dessa forma, pretende-se realizar neste estudo testes de cementação sólida em engrenagens cilíndricas de dentes retos (módulo 2) de aço SAE 8620 com aplicação de têmpera direta em óleo, objetivando selecionar num primeiro momento parâmetros geraram resultados no atendimento aos requisitos de dureza e profundidade da camada cementada para este tamanho de engrenagem.

\section{Materiais e métodos}

Na Tabela 1 é fornecida a composição química da barra de aço SAE 8620 (diâmetro de 50,8 mm) usada na fabricação das engrenagens cilíndricas de dentes retos,

Tabela 1. Composição química do aço SAE 8620 (\% peso), segundo dados do distribuidor de aços

\begin{tabular}{ccccccccc}
\hline $\mathbf{C}$ & $\mathbf{M n}$ & $\mathbf{S i}$ & $\mathbf{P}$ & $\mathbf{S}$ & $\mathbf{N i}$ & $\mathbf{M o}$ & $\mathbf{C r}$ & $\mathbf{C u}$ \\
\hline 0,19 & 0,76 & 0,26 & 0,010 & 0,014 & 0,47 & 0,18 & 0,52 & 0,06 \\
\hline Fo
\end{tabular}

Fonte: Radiaço - Comércio de Aços Especiais Ltda. 
segundo dados do distribuidor de aços. Trata-se de um aço ligado ao níquel, cromo e molibdênio, que pertence à série 86XX dos aços AISI-SAE. Este aço possui boas condições de temperabilidade e forjabilidade, sendo indicado para produção de peças cementadas.

O óleo usado na têmpera foi o South Oil Temp MO 32 fabricado pela Indústria Química Rocha Ltda., sendo recomendado para têmpera convencional de média velocidade ou também a frio (a temperatura do óleo não deve exceder $70^{\circ} \mathrm{C}$ ). A caixa utilizada para cementação sólida nas peças foi fabricada de chapas de aço SAE 1020 nas dimensões de $100 \times 100 \times 170,0 \mathrm{~mm}$ e espessura de $3,0 \mathrm{~mm}$; a mistura carburizante era o composto Cimentox (FL CIMENTOX1000, marca Oxigen).

O projeto das engrenagens foi executado baseado nas equações de Gieck [15], sendo estas fabricadas no Laboratório de Usinagem do Campus Jaraguá do Sul-Rau/IFSC. Basicamente as etapas foram: usinagem da barra até o diâmetro externo de $44,00 \mathrm{~mm}$; largura de face $12,50 \mathrm{~mm}$; fresamento dos dentes executado com uma fresa de perfil constante módulo 2; ângulo de pressão $20^{\circ}$; furação e corte; e os canais de chaveta foram feitos na máquina de eletroerosão a fio.

Cálculos teóricos baseados na segunda lei de Fick foram usados para se obter uma estimativa do tempo de difusão do carbono na fase Fe- $\gamma$ do aço SAE 8620 - é o tempo de permanência das peças dentro da mistura durante a cementação. A aplicação de condições de contorno específicas resultou na Equação $1[9,10]$ :

$$
\frac{C_{x}-C_{0}}{C_{S}-C_{0}}=1-e r f\left(\frac{x}{2 \sqrt{D t}}\right)
$$

onde $C_{x}$ é a concentração numa dada profundidade $x$ após um tempo $t ; D$ é o coeficiente de difusão, $C_{0}$ é a concentração inicial de átomos no sólido; $C_{\mathrm{s}}$ é a concentração constante na superfície do sólido.

Nos cálculos fixou-se o valor de $0,40 \mathrm{~mm}$ para a profundidade da camada endurecida por cementação (variável $x$ ). Mazzo [1] considera que para valores do módulo $(m)$ de rodas dentadas na faixa entre $2,0 \leq m<2,5$ se deve ter uma profundidade da camada cementada entre $0,40-0,60 \mathrm{~mm}$. No presente estudo com módulo 2 nos dentes das engrenagens, optou-se por fixar nos cálculos da Equação 1 tal profundidade próxima ao limite inferior desta faixa. Outros parâmetros mantidos nos cálculos foram: $0,19 \%$ para o teor inicial de carbono $\left(C_{o}\right) ; 1,225 \%$ para a solubilidade máxima de carbono $\left(C_{s}\right)$ na fase $\mathrm{Fe}-\gamma$ do aço SAE 8620 a $900^{\circ} \mathrm{C}$; e o coeficiente de difusão $(D)$ do carbono no $\mathrm{Fe}-\gamma$ a $900^{\circ} \mathrm{C}$ foi de $5,9 \times 10^{-12} \mathrm{~m}^{2} / \mathrm{s}$. O valor aproximado da solubilidade máxima de carbono (variável $C_{s}=1,225 \% \mathrm{C}$ ) foi obtido no gráfico visto na Figura 1. Ainda com relação ao parâmetro $C_{x}$, admite-se que a concentração de carbono na camada cementada pode ser controlada entre $0,7-1,0 \%$ (\%peso); porém, tal concentração no geral não deve exceder a $0,9 \%$ [16].

Os valores obtidos para os tempos de difusão do carbono na fase Fe- $\gamma$ do aço SAE 8620 (a $900^{\circ} \mathrm{C}$ ) usado nos experimentos de cementação sólida, e baseado nos cálculos aplicados à Equação 1 foram: 2h19min (variável $\left.C_{x}=0,40 \% \mathrm{C}\right) ; 2 \mathrm{~h} 51 \mathrm{~min}\left(C_{x}=0,45 \% \mathrm{C}\right)$; e de $3 \mathrm{~h} 29 \mathrm{~min}$ $\left(C_{x}=0,50 \% \mathrm{C}\right)$. Nestes valores não consta o tempo de molhamento (soaking time) com cerca de $1 \mathrm{~h}$ até ser atingido $900^{\circ} \mathrm{C}$ no forno. Na Tabela 2 são mostrados os conjuntos das variáveis de processo e os respectivos tempos obtidos nos cálculos da Equação 1.

Foram realizados testes com pares de amostras nos tempos de cementação pré-selecionados. Colocou-se uma camada da mistura carburizante com $20-25 \mathrm{~mm}$ de altura no fundo da caixa de aço SAE $1020(100 \times 100 \times 170 \mathrm{~mm}$, espessura $3 \mathrm{~mm}$ ), e as peças alojadas na posição horizontal ficando espaçadas por $20 \mathrm{~mm}$ entre si e entre as paredes da caixa; outra camada da mistura foi colocada acima das peças antes da caixa ser tampada - esta não era hermeticamente fechada, sendo a tampa do mesmo material. Cada conjunto foi

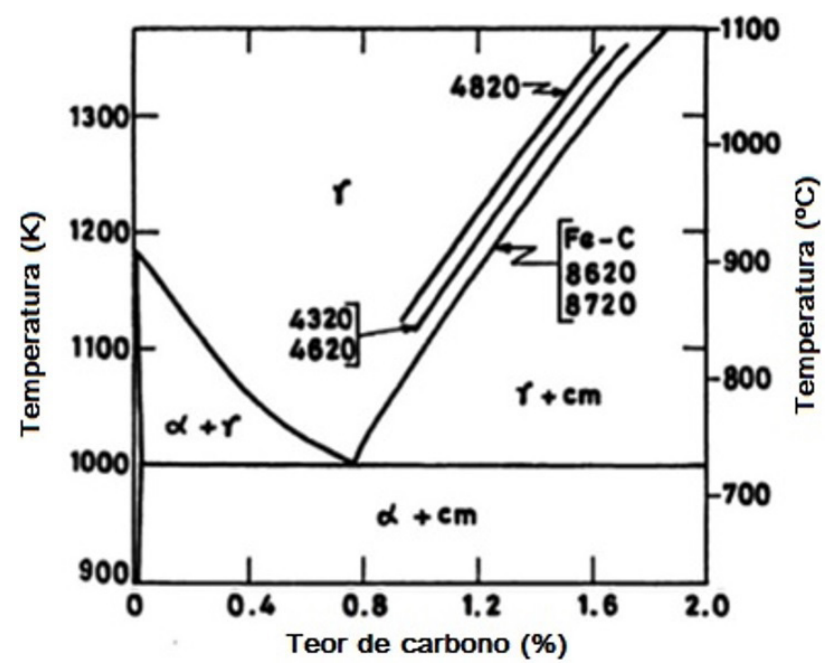

Figura 1. Parte do diagrama $\mathrm{Fe}-\mathrm{Fe}_{3} \mathrm{C}$ indicando o limite de solubilidade do carbono na fase austenita de alguns aços AISI em função da temperatura. Fonte: Adaptado de Hosseini e Li [7].

Tabela 2. Conjunto de variáveis usado nos cálculos da segunda lei de Fick para obtenção dos tempos de cementação sólida a $900^{\circ} \mathrm{C}$

\begin{tabular}{|c|c|c|c|c|}
\hline & $x(\mathrm{~m})$ & $C_{0}(\%$ peso $)$ & $C_{S}(\%$ peso $)$ & $\mathrm{D}\left(\mathrm{m}^{2} / \mathrm{s}\right)$ a $900^{\circ} \mathrm{C}$ \\
\hline Variáveis fixas nos cálculos da Equação 1 & $4 \times 10^{-4}$ & $0,19 \% \mathrm{C}$ & 1,225 & $5,9 \times 10^{-12}$ \\
\hline $\begin{array}{l}\text { Valores da variável } C_{x} \text { e tempos obtidos para nos } \\
\text { cálculos da Equação } 1\end{array}$ & \multicolumn{2}{|c|}{$\begin{array}{l}C_{x}=0,40 \% \mathrm{C} \\
C_{x}=0,45 \% \mathrm{C} \\
C_{x}=0,50 \% \mathrm{C}\end{array}$} & \multicolumn{2}{|c|}{$\begin{array}{l}\text { tempo }(t)=2 \mathrm{~h} 19 \mathrm{~min} \\
\text { tempo }(t)=2 \mathrm{~h} 51 \mathrm{~min} \\
\text { tempo }(t)=3 \mathrm{~h} 29 \mathrm{~min}\end{array}$} \\
\hline
\end{tabular}


aquecido até $900^{\circ} \mathrm{C}$ e, então, marcou-se o tempo de cementação no forno de tratamento térmico (marca QUIMIOS). Após este período, as peças foram removidas e aplicou-se têmpera direta em óleo (têmpera a frio); as peças temperadas foram limpas e revenidas a $180^{\circ} \mathrm{C}$ por $1 \mathrm{~h}$.

As práticas executadas no Laboratório de Ensaios e Materiais do Campus foram: remoção de amostras das peças cementadas; embutimento (baquelite); lixamento (grana 80 até 1200) e polimento em suspensão de alumina $1,0 \mu \mathrm{m}$; ataque químico por imersão a frio em Nital $2 \%$ por 4 s; estereoscópio (marca ZEISS, modelo Stemi 2000-C) para macrografia; análise por microscopia óptica; microdurômetro (Future-Tech Corp., modelo FM-800) usado na escala Rockwell C (HRC) com carga de 300 gf por $10 \mathrm{~s}$ (média de três medições). Tal carga proporcionou diagonais retas na impressão deixada pelo penetrador Vickers do equipamento.

\section{Resultados e discussão}

\subsection{Análise por macrografia}

As macrografias vistas nas Figuras 2, 3 e 4 foram obtidas após os testes de cementação sólida a $900^{\circ} \mathrm{C}$ na condição da variável $C_{x}=0,40 \% \mathrm{C}(\operatorname{amostras} 1 \mathrm{e} 2), C_{x}=0,45 \% \mathrm{C}$ (amostras 3 e 4$)$ e $C_{x}=0,50 \% \mathrm{C}(\operatorname{amostras} 5$ e 6$)$, respectivamente. Notou-se que se formou uma região contínua e homogênea abaixo da superfície e ao longo do contorno dos dentes das engrenagens nas condições testadas. Tal fato provavelmente foi influenciado pela difusão de carbono atômico para o interior das peças durante a cementação e pela subsequente aplicação da têmpera.

A homogeneidade na profundidade de camadas cementadas é um fator bastante relevante, pois a vida útil da
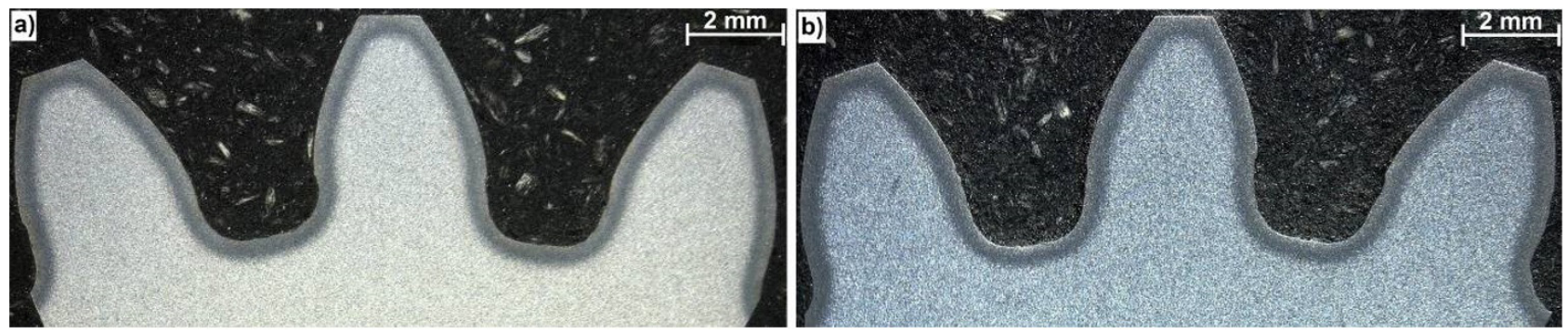

Figura 2. Macrografias na condição da variável $C_{x}=0,40 \% \mathrm{C}$ e cementação por $2 \mathrm{~h} 19 \mathrm{~min}$ a $900^{\circ} \mathrm{C}$ (ver dados na Tabela 2): (a) amostra-1; (b) amostra-2. Ataque Nital $2 \%$.
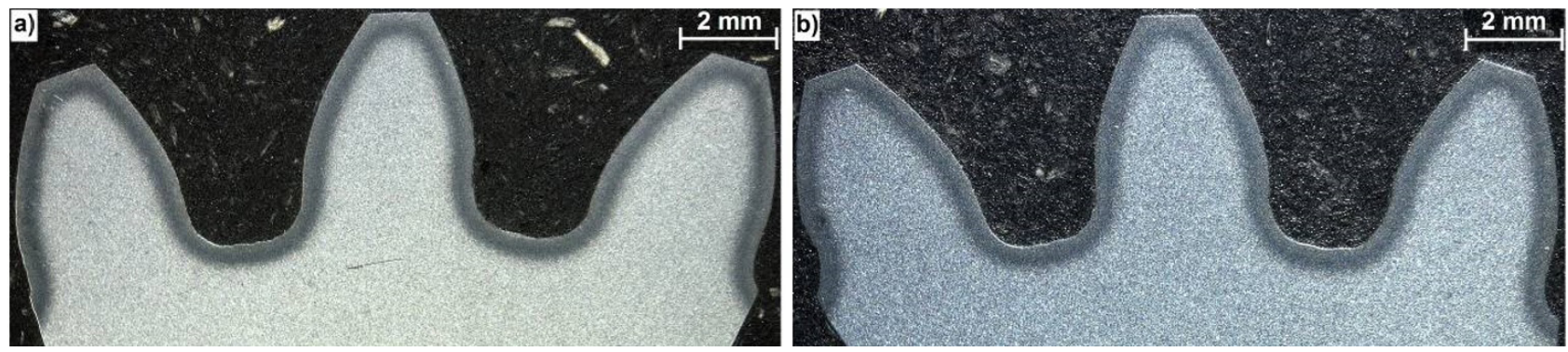

Figura 3. Macrografias na condição da variável $C_{x}=0,45 \% \mathrm{C}$ e cementação por $2 \mathrm{~h} 51 \mathrm{~min}$ a $900^{\circ} \mathrm{C}$ (ver dados na Tabela 2): (a) amostra-3; (b) amostra-4. Ataque Nital 2\%.
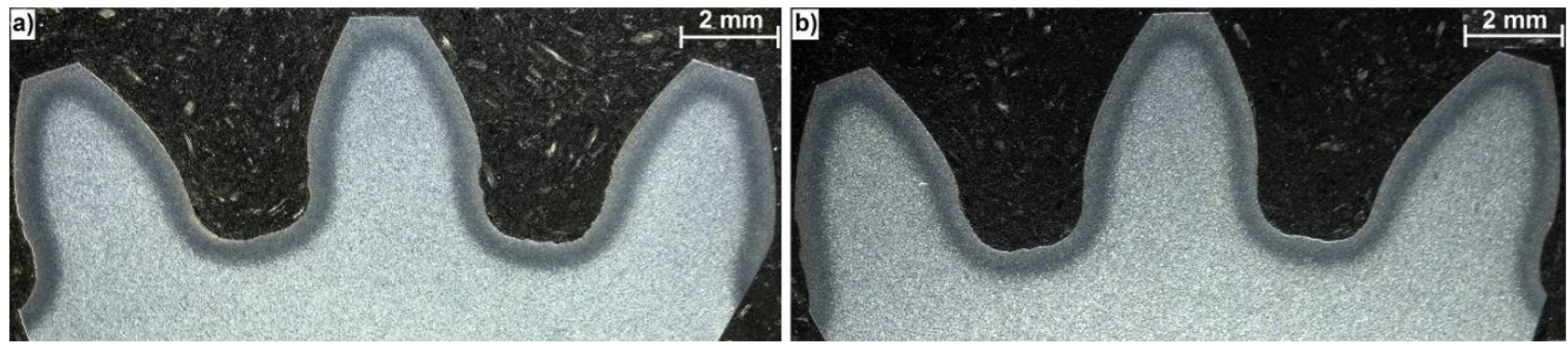

Figura 4. Macrografias na condição da variável $C_{x}=0,50 \% \mathrm{C}$ e cementação por $3 \mathrm{~h} 29 \mathrm{~min}$ a $900^{\circ} \mathrm{C}$ (ver dados na Tabela 2): (a) amostra-5; (b) amostra-6. Ataque Nital 2\%. 
engrenagem será afetada se houver regiões muito espessas ou estreitas - para uma penetração insuficiente de carbono na base do dente pode haver uma falha prematura em serviço, e uma penetração excessiva na ponta do dente também pode fragilizar a peça [6].

\subsection{Análise por microscopia óptica}

As Figuras 5 e 6 mostram micrografias das amostras- 1 e 2 feitas no topo do dente das peças cementadas por $2 \mathrm{~h} 19 \mathrm{~min}$ a $900^{\circ} \mathrm{C}$ (variável $C_{x}=0,40 \% \mathrm{C}$ ). Nas micrografias das Figuras 5a e 5c notou-se a formação de regiões distintas: camada cementada junto à superfície (região-1); uma zona de transição (região-2); e a região no núcleo do dente (região-3). Nas Figuras 5 b e 5 d destaca-se a formação de uma microestrutura homogênea junto à superfície dos dentes. Na Figura 6 são vistas micrografias de maior ampliação, mostrando que na região-1 se formou uma microestrutura martensítica contendo regiões claras dispersas na matriz. Tais áreas claras provavelmente contêm percentuais de austenita retida. Pode-se dizer que a presença de martensita na região contínua abaixo do perfil dos dentes foi resultado da têmpera direta em óleo, evidenciando que houve suficiente difusão de carbono para o interior do material devido à cementação. O exame metalográfico na região- 2 destacou a formação de martensita fina, e na região-3 uma matriz de perlita e ferrita.

As micrografias nas Figuras 7 e 8 se referem às amostras- 3 e 4 (condição da variável $C_{x}=0,45 \% \mathrm{C}$, $t=2 \mathrm{~h} 51 \mathrm{~min})$ e às amostras- 5 e $6\left(C_{x}=0,50 \% \mathrm{C}, t=3 \mathrm{~h} 29 \mathrm{~min}\right)$, respectivamente. $\mathrm{O}$ exame metalográfico nestes dois pares de amostras em regiões junto à superfície dos dentes indicou a formação de placas de martensita contendo provável dispersão de austenita retida na matriz. Notou-se uma maior concentração destas regiões claras dispersas na matriz quando junto à superfície em comparação à região na zona de transição próxima ao núcleo do dente. Estes resultados foram similares àqueles verificados no exame das amostras-1 e 2 (visto nas Figuras 5 e 6 ).
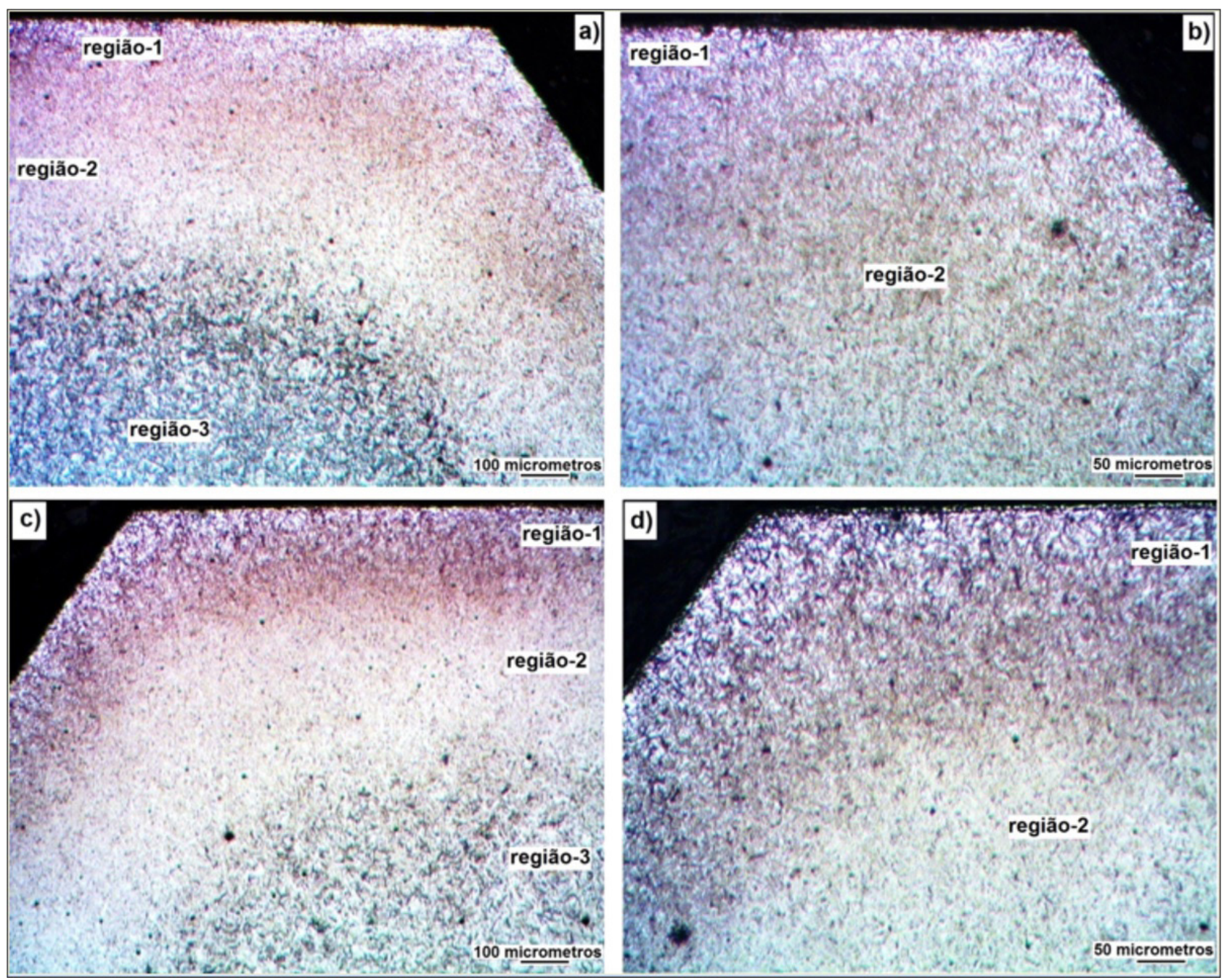

Figura 5. Micrografias no topo do dente da engrenagem na condição $C_{x}=0,40 \% \mathrm{C}$ (cementação por $2 \mathrm{~h} 19$ min a $900^{\circ} \mathrm{C}$ ): (a) amostra-1, aumento 100X; (b) mesma região, aumento 200X; (c) amostra-2, aumento 100X; (d) mesma região, aumento 200X. Ataque Nital $2 \%$. 

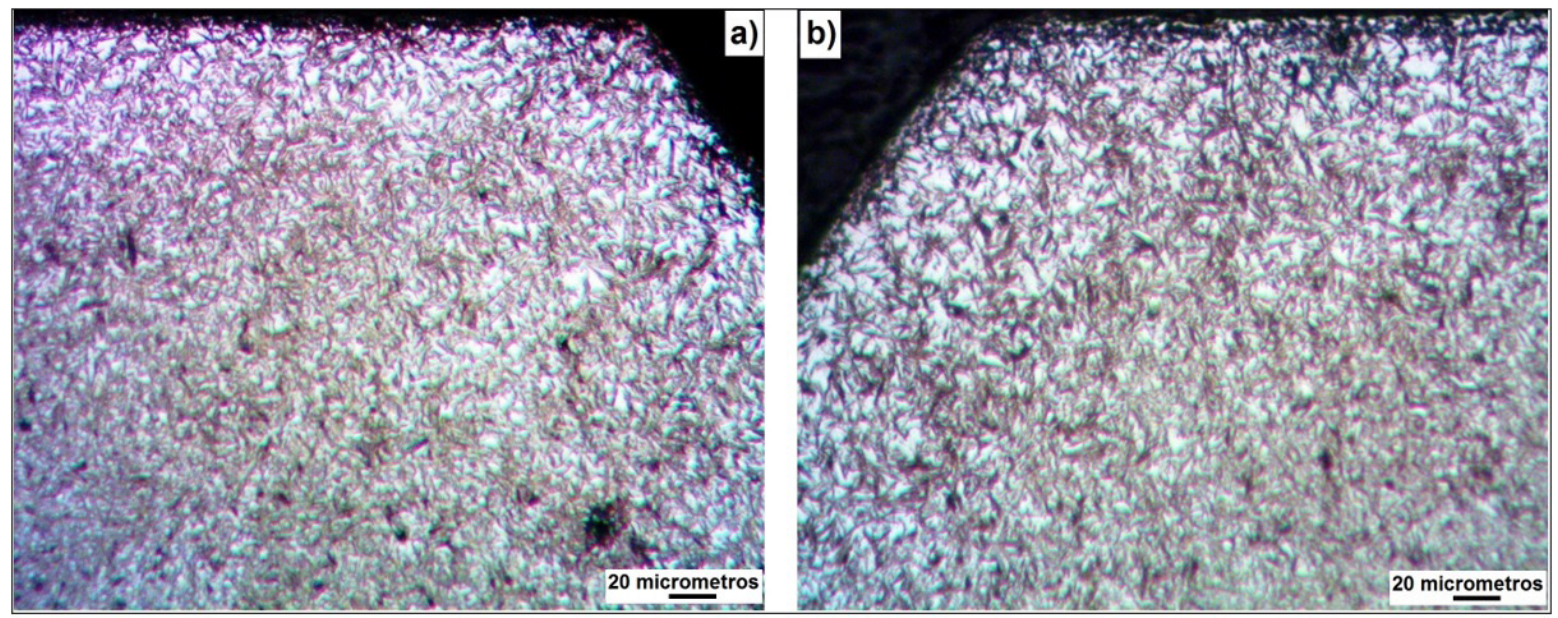

Figura 6. Micrografias no topo do dente, condição $C_{x}=0,40 \% \mathrm{C}$ (ampliação das regiões na Figura 5): (a) amostra-1; (b) amostra-2. Microestrutura na camada cementada junto à superfície com placas de martensita e provável dispersão de austenita retida (áreas claras). Aumento 400X; ataque Nital 2\%.
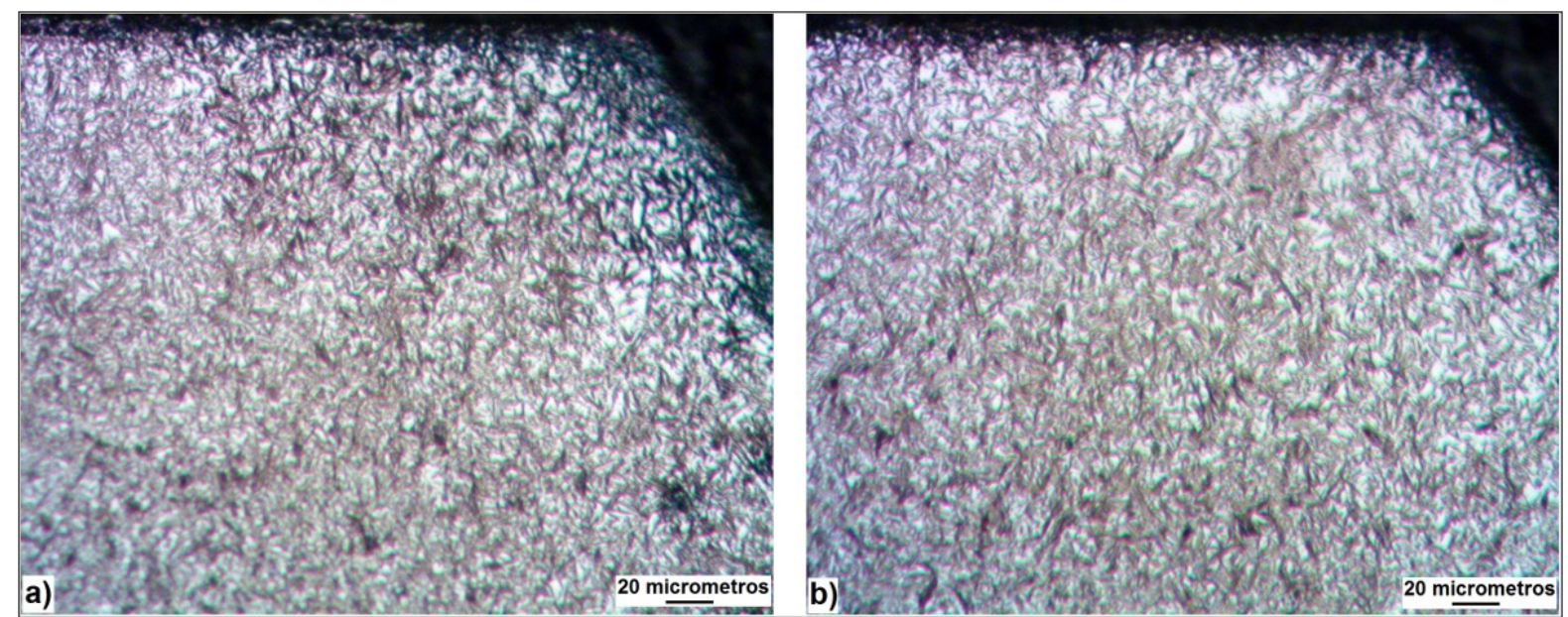

Figura 7. Micrografias no topo do dente, condição $C_{x}=0,45 \% \mathrm{C}$ e cementação por $2 \mathrm{~h} 51 \mathrm{~min}$ a $900^{\circ} \mathrm{C}$ : (a) amostra-3; (b) amostra-4. Microestrutura na camada cementada junto à superfície com placas de martensita e provável dispersão de austenita retida (áreas claras). Aumento 400X; ataque Nital 2\%.
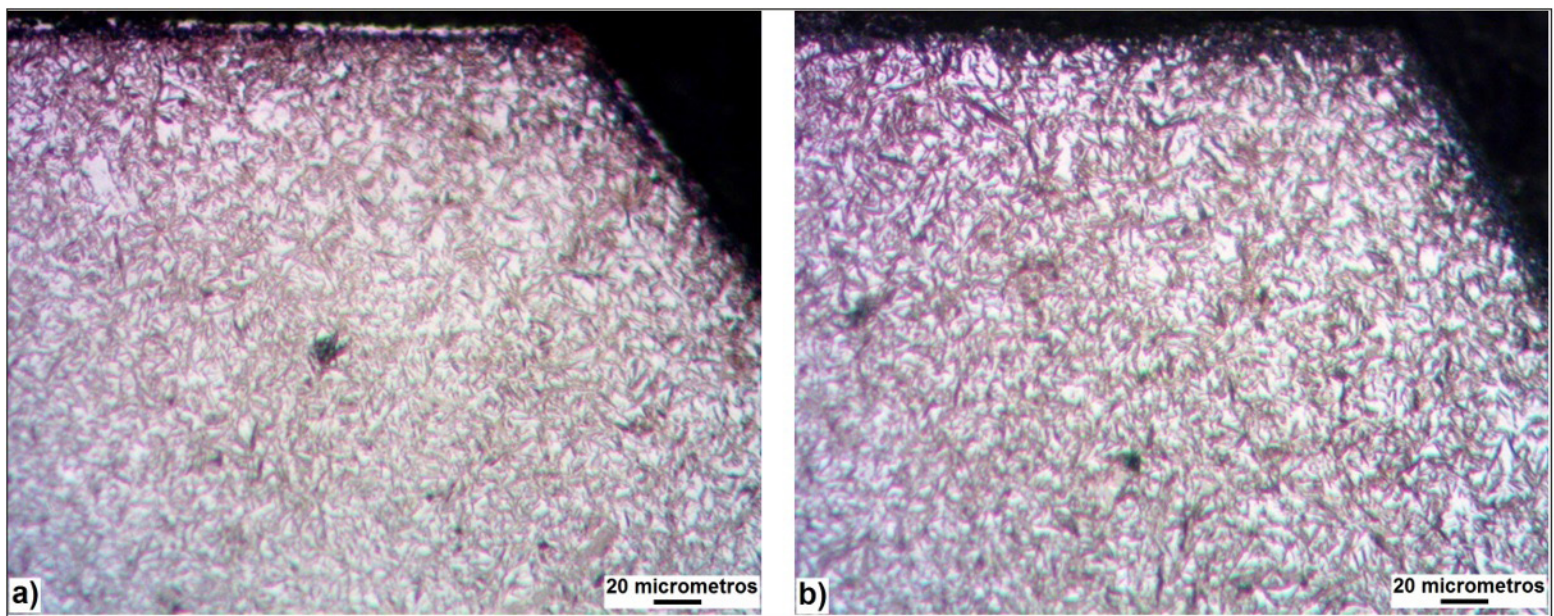

Figura 8. Micrografias no topo do dente, condição $C_{r}=0,50 \% \mathrm{C}$ e cementação por $3 \mathrm{~h} 29 \mathrm{~min}$ a $900^{\circ} \mathrm{C}$ : (a) amostra-5; (b) amostra-6. Microestrutura na camada cementada junto à superfície com placas de martensita e provável dispersão de austenita retida (áreas claras). Aumento 400X; ataque Nital $2 \%$. 
Davis [5] registrou a presença de austenita retida entre placas de martensita na região junto à superfície numa amostra de aço AISI 8719, submetida à têmpera direta após cementação a gás onde tal fase não foi atacada pelo reagente nital (coloração clara nas micrografias). A formação desta fase também foi notada no estudo de Bepari [12], quando na análise metalográfica de um aço baixa-liga ao níquel cementado a gás. Garcia et al. [13] e Cardoso et al. [14] também notaram a distribuição de regiões claras dispersas na matriz martensítica junto à superfície dos dentes de engrenagens cilíndricas de dentes retos de aço SAE 4320, tratadas por cementação sólida a $900^{\circ} \mathrm{C}$ e submetidas à têmpera direta em óleo a partir desta temperatura.

Alguns autores consideram que a tendência à formação de austenita retida na microestrutura martensítica em aços cementados pode ocorrer pela [6,12]: influência dos teores de elementos de liga em alguns aços (ação do cromo e níquel; e no caso do carbono mais alto, p.ex.); e aplicação da têmpera direta em óleo, não sendo no geral recomendada após cementação. Davis [5] sugere que pode haver alguma austenita retida junto à superfície dos dentes de engrenagens de aço cementadas, sendo que tal fase em quantidades de $15-20 \%$ em volume não é prejudicial para a resistência à fadiga dos dentes. A retenção de austenita reduz o nível de tensões residuais geradas na martensita, aumentando a tenacidade da camada cementada; entretanto, tal fase causa uma diminuição na dureza superficial das peças não sendo desejável na vida útil em fadiga $[5,6]$. Uma quantidade excessiva de austenita retida $(\geq 40 \%)$ pode reduzir as tensões residuais compressivas na superfície e contribuir para o decréscimo da resistência à fadiga [12]. No presente estudo não foram medidos os percentuais de austenita retida nas condições testadas.

\subsection{Perfis de dureza}

Na Figura 9 são mostrados os perfis de dureza para as amostras-1 e 2 (variável $C_{x}=0,40 \% \mathrm{C}$ e $t=2 \mathrm{~h} 19 \mathrm{~min}$ ), sendo as medidas feitas do topo para o meio dos dentes das peças cementadas. Notou-se que até as profundidades de $0,45 \mathrm{~mm}$ e $0,50 \mathrm{~mm}$ foram obtidos valores de dureza acima de $50 \mathrm{HRC}$, respectivamente nas Figura 9a e 9b. Os valores tomados próximo à superfície dos dentes (até $\approx 0,05 \mathrm{~mm}$ ) ficaram na faixa de 53-58 $\mathrm{HRC}$, enquanto na profundidade entre $0,1-0,3 \mathrm{~mm}$ foram anotados os maiores valores entre 60-62 HRC.

Os perfis de dureza apresentados na Figura 10 são representativos dos pares de peças cementadas a $900^{\circ} \mathrm{C}$ por $2 \mathrm{~h} 51 \mathrm{~min}$ (variável $C_{x}=0,45 \% \mathrm{C}$, ver Figura 10a) e por $3 \mathrm{~h} 29 \mathrm{~min}\left(C_{x}=0,50 \% \mathrm{C}\right.$, ver Figura $\left.10 \mathrm{~b}\right)$, igualmente para medições do topo para a metade dos dentes. Na condição indica pela Figura 10a foram registrados valores de dureza acima de $50 \mathrm{HRC}$ até profundidades de $0,50 \mathrm{~mm}$; os valores anotados junto à superfície dos dentes (até $\approx 0,05 \mathrm{~mm}$ ) foram de $\approx 55 \mathrm{HRC}$, e na profundidade entre $0,1-0,3 \mathrm{~mm}$ a dureza ficou na faixa de 61-62,5 HRC. E na condição de cementação representada na Figura 10b, registrou-se valores acima de $50 \mathrm{HRC}$ até profundidades de $0,80 \mathrm{~mm}$; junto à superfície dos dentes (até $\approx 0,05 \mathrm{~mm}$ ) a dureza foi de $\approx 56$ HRC, enquanto na profundidade entre $0,1-0,4 \mathrm{~mm}$ a dureza ficou entre 60-63 HRC.

A profundidade da camada endurecida por cementação em engrenagens pode ser estimada em função do tamanho do módulo do dente. Neste estudo, a profundidade desta camada foi estimada pela variável $x$, aplicada nos cálculos da Equação 1, onde o módulo vale 2,0 (variável $m$ ). Mazzo [1] sugere que para valores do módulo na faixa $2,0 \leq m<2,5$ a profundidade desta camada deve ficar entre $0,40-0,60 \mathrm{~mm}$ para a melhor vida útil das peças. Outros autores sugerem que tal camada cementada deve possuir valores de dureza no mínimo acima de $50 \mathrm{HRC}(\approx 550 \mathrm{HV})$, sendo a profundidade efetiva dessa camada medida a partir deste valor $[7,10]$. Garcia et al. [13] e Cardoso et al. [14] também anotaram valores de dureza acima de $50 \mathrm{HRC}$ na faixa de $0,40-0,60 \mathrm{~mm}$ na cementação sólida de engrenagens de módulo 2 .
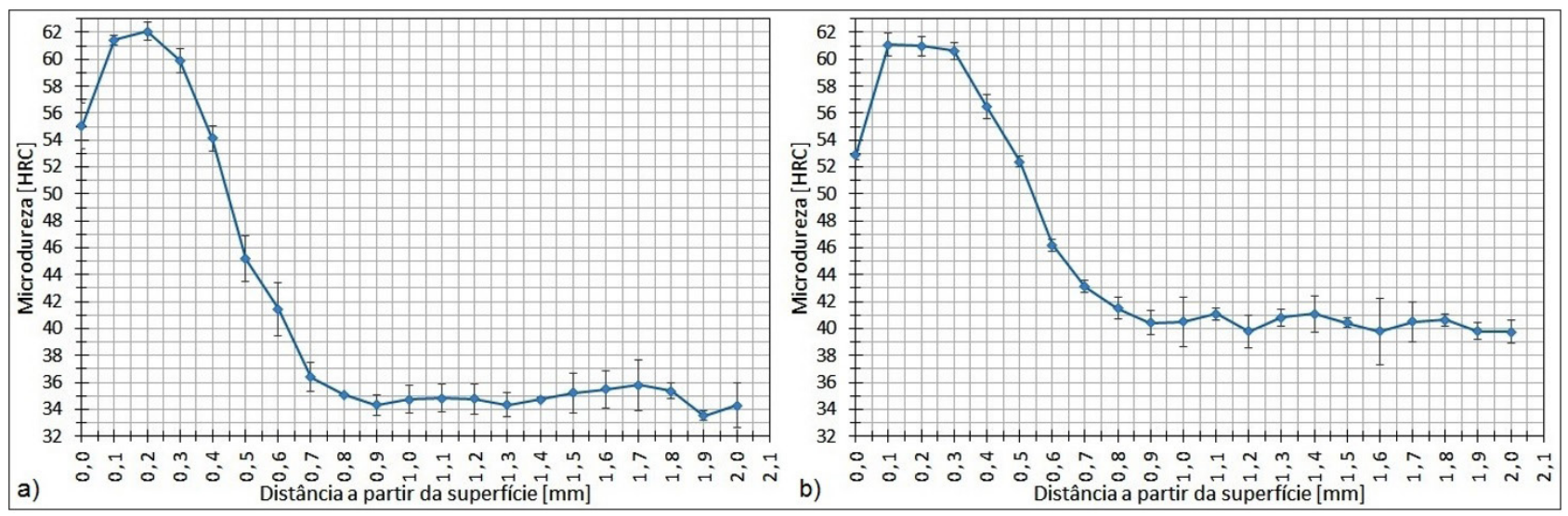

Figura 9. Perfis de microdureza do topo para o interior dos dentes das engrenagens (cementação sólida por $2 \mathrm{~h} 19 \mathrm{~min}$ a $900^{\circ} \mathrm{C}$, variável $C_{x}=0,40 \%$ C): (a) amostra-1; (b) amostra-2. 

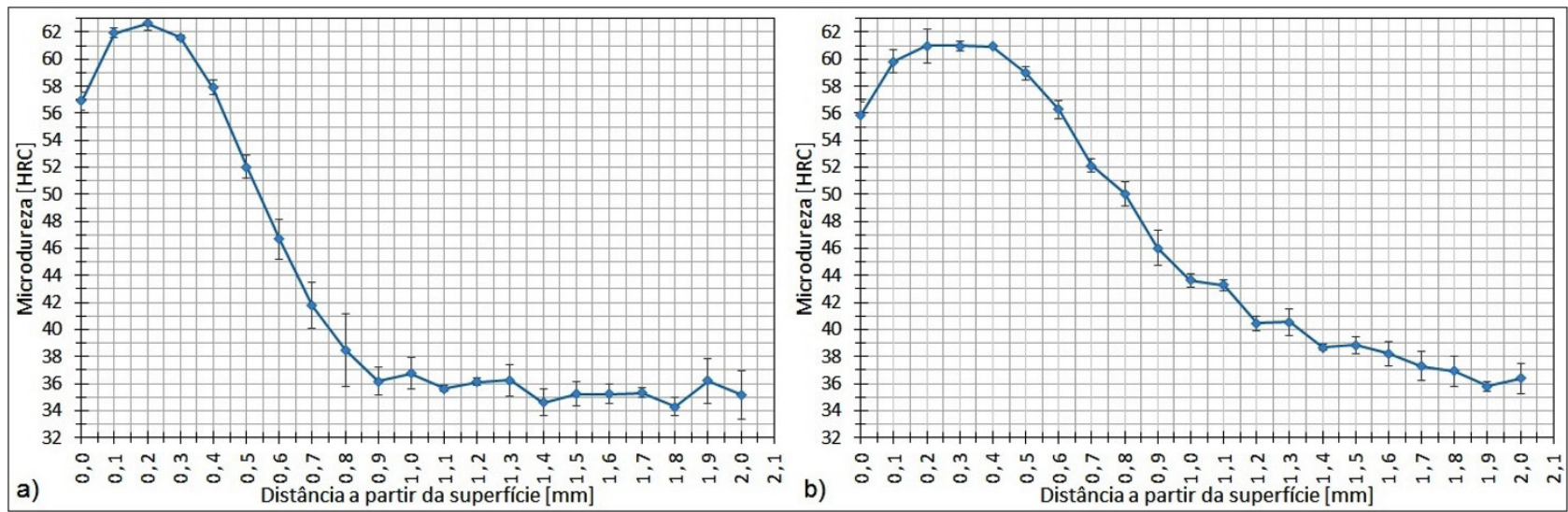

Figura 10. Perfis de microdureza do topo para o interior dos dentes: a) amostra-3 (cementação por $2 \mathrm{~h} 51 \mathrm{~min}$ a $900^{\circ} \mathrm{C}, C_{x}=0,45 \% \mathrm{C}$ ); (b) amostra-5 (cementação por $3 \mathrm{~h} 29 \mathrm{~min}$ a $900^{\circ} \mathrm{C}, C_{x}=0,50 \% \mathrm{C}$ ).

Nos estudos de Garcia et al. [13] e Cardoso et al. [14] foi admitida a possibilidade de formação de austenita retida entre placas de martensita em amostras submetidas à têmpera direta logo após cementação sólida; os ensaios de microdureza nestes estudos registraram uma leve queda na dureza superficial da camada cementada junto à superfície dos dentes em profundidades de até $0,05 \mathrm{~mm}$. No presente estudo, o registro dos menores valores de dureza junto à superfície dos dentes das peças cementadas também pode ser um indicativo da presença de austenita retida, favorecida pela aplicação de têmpera direta. Mesmo assim, tais os valores de dureza ficaram acima de $50 \mathrm{HRC}$ e, então, atenderam o requisito adotado neste estudo. Na região do núcleo dos dentes os resultados de dureza ficaram dentro do esperado, segundo dados da literatura.

Houve uma transição gradual nos valores de dureza medidos a partir da superfície para a região no núcleo dos dentes. No caso de aços usados para fabricação de engrenagens cementadas, tem-se que a dureza próxima ao núcleo da peça pode variar entre 32-48 HRC [6].

Os resultados apresentados nos perfis de microdureza para a cementação na condição da variável $C_{x}$ igual a $0,40 \% \mathrm{C}$ e $0,45 \% \mathrm{C}$ foram satisfatórios, pois ambos os testes resultaram valores de dureza acima de $50 \mathrm{HRC}$ com profundidades na faixa de 0,40-0,60 mm. Entretanto, os resultados na condição $C_{x}=0,50 \% \mathrm{C}$ não foram satisfatórios. Porque as profundidades atingidas pela camada (valores $\approx 0,80 \mathrm{~mm}$ ) ultrapassaram o critério especificado para módulo 2 , ou seja, houve uma difusão de carbono relativamente excessiva neste maior tempo de cementação.

\section{Conclusões}

Os resultados foram satisfatórios para a cementação sólida de engrenagens cilíndricas de dentes retos (módulo 2) com o conjunto de parâmetros: $C_{x}=0,40 \% \mathrm{C}$ e $t=2 \mathrm{~h} 19 \mathrm{~min}$ a $900^{\circ} \mathrm{C}$. Porque os valores de dureza obtidos na camada cementada ficaram acima de $50 \mathrm{HRC}$ até profundidades na faixa de $0,45-0,50 \mathrm{~mm}$ e, portanto, próximo do limite inferior na faixa de $0,40-0,60 \mathrm{~mm}$ que é requisito para o módulo entre $2,0 \leq m<2,5$.

Formou-se uma região contínua e homogênea logo abaixo da superfície e ao longo do contorno dos dentes das peças cementadas nas três condições testadas. A análise metalográfica revelou a formação três regiões a partir do topo para o interior dos dentes: placas de martensita contendo dispersão de regiões claras; uma zona de transição com martensita fina; e no núcleo dos dentes com perlita e ferrita. Notou-se haver uma maior concentração destas regiões claras na matriz de martensita próxima à superfície. Tais áreas claras podem conter percentuais de austenita retida, como resultado da têmpera direta subsequente à cementação sólida. Os níveis de austenita retida não foram medidos neste trabalho. Para um trabalho futuro pretende-se determinar percentuais de austenita retida e verificar a reprodutibilidade dos resultados satisfatórios para engrenagens de maior largura de face.

\section{Agradecimentos}

Os autores agradecem ao Instituto Federal de Santa Catarina (pela utilização dos laboratórios de usinagem, e de ensaios dos materiais do Campus Jaraguá do Sul-Rau), pelo auxílio financeiro ao pesquisador e pela bolsa PIBITI financiada pelo CNPq no edital n ${ }^{\circ}$ 02/2019/PROPPI/IFSCUniversal para realização deste trabalho.

\section{Referências}

1 Mazzo N. Engrenagens cilíndricas: da concepção à fabricação. São Paulo: Blucher; 2013.

2 Norton RL. Projeto de máquinas: uma abordagem integrada. 4. ed. Porto Alegre: Bookman; 2013. 
3 Rakhit AK. Heat treatment of gears: a practical guide for engineers. Ohio: ASM International; 2000.

4 Colpaert H. Metalografia dos produtos siderúrgicos comuns. 4. ed. São Paulo: Edgard Blucher; 2008.

5 Davis JR. Gear materials, properties and manufacture. Ohio: ASM International; 2005.

6 Chiaverini V. Aços e ferros fundidos. 7. ed. São Paulo: ABM; 2002.

7 Hosseini SRE, Li Z. Pack carburizing: characteristics, microstructure and modeling. In: Colas R, Totten GE, editors. Encyclopedia of iron, steel and their alloys (online version). Boca Raton: CRC Press; 2016. p. 1-24.

8 Gupta GS, Hosmani SS, Sarkar S. Carburizing: pack. In: In: Colas R, Totten GE, editors. Encyclopedia of iron, steel and their alloys (online version). Boca Raton: CRC Press; 2015. p. 643-651.

9 Callister WD Jr, Rethwisch DG. Ciência e engenharia de materiais: uma introdução. 8. ed. Rio de Janeiro: LTC; 2015.

10 Hosseini SRE. Simulation of case depth of cementation steels according to Fick's laws. Journal of Iron and Steel Research. 2012;19(11):71-78.

11 Costa e Silva ALV, Mei PR. Aços e ligas especiais. 3. ed. São Paulo: Edgard Blucher; 2010.

12 Bepari MMA. Carburizing: a method of case hardening of steel. In: Hashmi S, editor. Comprehensive materials finishing. Vol. 2. Bangladesh: Elsevier Inc.; 2017. p. 71-106.

13 Garcia NG, Lopes PEK, Pimenta JS. Análise da cementação sólida em engrenagens cilíndricas de dentes retos de aço SAE 4320 - parte 1. Revista Técnico-Científica do CREA-PR. 2018;13:1-20.

14 Cardoso J, Fertig BL, Castaldo EC, Pimenta JS. Análise da cementação sólida em engrenagens cilíndricas de dentes retos de aço SAE 4320 - parte 2. Revista Técnico-Científica do CREA-PR. 2019;22:1-15.

15 Gieck K. Manual de fórmulas técnicas. 4. ed. São Paulo: Hemus, 1996.

16 Lampman S. Introduction to surface hardening of steels. In: ASM International, editor. ASM handbook: Heat treating. Vol. 4A. Ohio: ASM International; 1991; p. 259-267.

Recebido em: 3 Abr. 2020

Aceito em: 10 Set. 2020 